\title{
LA LUCHA POR EL PODER MUNDIAL Y EL ARMAMENTISMO
}

Lic. ARTURO BONILLA SÁNCHEZ *

\section{INTRODUCCIÓN}

El propósito principal de este trabajo es el de avanzar en el análisis de un fenómeno sumamente delicado y complejo, como es la lucha por el poder y la hegemonía mundiales, la cual parece estarse convirtiendo en una verdadera amenaza para la humanidad, en la medida en que aquélla continúa, a pesar de haber concluido en lo fundamental la guerra fría, suceso sobre el cual mucho se ha escrito y especulado, pues es un asunto de importancia histórica que ha sido capaz de modificar el eje fundamental en que descansaba la política mundial: el bipolarismo.

La premisa fundamental parte del supuesto de que, en la posguerra fría, se ha generado una intensa competencia en la opción de exportar armamento, sobre todo armas mayores y tecnologías militares, la cual es contantemente fortalecida, como se estudia en los trabajos de este volumen. Cabe destacar que esta vertiente del comercio está incluida en la guerra en los niveles productivos, financieros, comerciales o tecnológicos.

Asimismo se ha establecido una competencia de carácter militar, para mantenerse en la punta de la investigación y producción de nuevas armas ${ }^{1}$ a fin de disuadir a posibles o potenciales enemigos, pero también para su comercialización, pues de acuerdo con la estrategia y la geopolítica de largo aliento que han contenido emergencias políticas momen-

*Investigador titular y ex director del Instituto de Investigaciones Económicas, UNAM. El autor agradece el apoyo que brindó la maestra Margot Sotomayor Valencia en la elaboración de este trabajo. táneas, la opción de exportar armas puede ser conveniente con fines meramente comerciales cuando ese mercado específico es favorable. Cabe recordar que esta vertiente del comercio está incluida en la guerra económica entre las grandes potencias del mundo: Estados Unidos, el Reino Unido, Francia, China, Rusia, Alemania y Japón. Las cinco primeras han sido las exportadoras más importantes de armamento pesado al llamado Tercer Mundo, además de ser las principales potencias militar-nucleares y miembros permanentes del Consejo de Seguridad (CS) de las Naciones Unidas (ONU).

En el ámbito competitivo en general, esas potencias, con excepción de Rusia, aportan más del $70 \%$ al producto mundial, junto con otros países de menor peso, como Canadá e Italia.

1. Se entiende que se trata de armas convencionales, tanto pesadas como ligeras pero pueden ser armas de exterminio masivo no necesariamente nucleares. La reciente revisión llevada a cabo con renovado consenso sobre el Tratado de No Proliferación Nuclear (TNPN) está destinada (con todos los elementos contradictorios que existen a frenar la tendencia que se había venido generando en algunos países del llamado Sur, que comprende a algunos del Medio Oriente, de importar tecnologías nucleares "capaces de producir armas nucleares"). Hoy día todos los países del Oriente Medio son partidarios de la creación de una zona libre de armas nucleares, aunque el caso de Israel es ambivalente e invita a desplegar, como lo ha hecho uno u otro país de la zona, instrumentos políticos de presión que pueden ser falaces, ya que las tecnologías nucleares para usos civiles no equivalen a "tecnologías para la bomba". Mientras se les atribuyen errónea o realmente esas intenciones, se demora el momento del consenso para la creación, allí de una zona libre de armas nucleares. 
Otro dato que conviene mencionar es que los países señalados también fueron los principales protagonistas de los dos más grandes conflictos bélicos que han afectado a la humanidad: la primera y segunda guerras mundiales, con la excepción de China y Canadá, que en esas guerras estaban total o parcialmente dominados por otras potencias. El origen y desenvolvimiento posterior de esas potencias puede hacerse residir en la competencia y rivalidad comercial, financiera, tecnológica, militar y política.

Tal parece que en la actualidad las consecuencias político-militares de la creciente competencia entre los bloques económicos capitaneados por algunas de las grandes potencias del orbe es el más importante desafío, de los muchos que azotan a la humanidad, para unas expectativas de paz en tanto y cuanto las tendencias de la revolución tecnológica son a volcarse en la industria militar. Así, entre las diversas vías con que se tiende a contrarrestar las crisis recurrentes del mercado mundial está el comercio de armamento o de la electrónica aplicada al Departamento de la Defensa de Estados Unidos por relevantes corporaciones privadas no solamente de este país, sino de otras potencias, como Japón. ${ }^{2}$

Si viviéramos en un mundo de creciente colaboración social y económica entre empresas, regiones y países, donde los mayores y mejores esfuerzos se apostaran a alcanzar el paradigma del desarrollo económico y social, sin necesidad de entrar en la competencia salvaje, no habría bases para que los grupos políticos y económicos más poderosos del planeta tomaran sus decisio-

2. Sobre el papel que desempeñan los tanques de pensamiento, como la Rand Corporation y la Heritage Foundation en la ideología y los negocios de las grandes corporaciones, véase Luis Gonzáles Souza,. "México desde EU: ¿estabilidad sin democracia?, en Estrategia, núm. 113, México, septiembre-octubre de 1993. nes en torno a la necesidad de incrementar su poderío militar. Como ello no está ocurriendo y no hay posibilidad de cambios debido a que la producción y el mercado están indisolublemente ligados entre sí, y con la producción y exportación de armamentos, se entienden los crecientes peligros que la humanidad enfrenta para garantizar su simple supervivencia como civilización, en la medida en que es cada vez mayor la capacidad de destrucción derivada de la producción de armas letales y no letales (las capaces de asegurar sólo la destrucción de bienes). Ello por cuanto en la propia destrucción va involucrada una necesidad intrínseca: la de renovar la valorización del capital en el siguiente ciclo, por ejemplo, con la reconstrucción. $^{3}$

Es un contrasentido que en vez de destinar recursos financieros a la solución de los más graves problemas que en tanto sujetos sociales nos aquejan, los estados destinen presupuestos enormes a los establecimientos de defensa, a los medios de destrucción: la liberalización comercial mun-dial lo debiera hacer innecesario. Pero la realidad es muy distinta, ya que la competencia exacerbada también alimenta el nacionalismo, como la prueba el que la Unión Europea (UE) como bloque económico, se ha enfrentado a inmensas dificultades que pusieron en riesgo la unificación monetaria iniciada en 1999.

3. Véase Adolfo Kozlik, El capitalismo del desperdicio, México, Siglo XXI Editores, 1968. En relación con la posibilidad de reducir tal capacidad de destrucción y obtener unos dividendos de paz, después de la guerra fría, el Fondo Monetario Internacional (FMI) advierte, en un estudio de 1992, que es muy importante la diferencia entre "reducir unilateralmente la capacidad de destrucción por un solo país o grupo de países al disminuir su gasto militar, frente a reducir dicha capacidad y gasto a nivel mundial". Véase "Beneficios económicos de la reducción del gasto militar", en FMI, Perspectivas de la economía mundial, Estudios Económicos y Financieros, octubre de 1993. Se 
Es relevante destacar que sólo en círculos muy reducidos de esos países se da importancia a lo que se avanza en materia de medios tecnológicos-militares industriales para los establecimientos de la defensa, incluidas las pruebas para lanzar las nuevas líneas de armamento y su posterior producción y resguardo. Todo se lleva a efecto en los marcos del mayor secreto posible -ese a su necesaria autorización anual por el Congreso, por ejemplo, en Estados Unidos-, de modo ambiguo: a] para que la opinión pública se informe mal acerca de los riesgos mayores, y $b$ ] sería una estrategia disuasiva de seguridad.

Así, se observa que a lo largo de la década de los noventa continúa la investigación y la producción de armas, sin duda cada vez más eficaces como medios de exterminio, a pesar de que dicha década se caracteriza por la desintegración de uno de los polos del conflicto -que justificaban dichas erogaciones-, la Unión Soviética, y que generó la esperanza de que por fin se llegaba a un punto final de la carrera armamentista nuclear y convencional desatada entre las anteriores superpotencias, y a la que se sumaron otras naciones con armas nucleares aliadas en la Organización del Tratado del Atlántico Norte (OTAN) o el Pacto de Varsovia (PV).

La carrera armamentista convencional, pese a las expectativas optimistas de la posguerra fría, continuaría -aun en el caso de

sostiene allí que "una reducción del $20 \%$ del gasto militar mundial podría generar a largo plazo un aumento del consumo y la inversión privados de casi 1 y $2 \%$, respectivamente. A su vez, dichos aumentos generan la mayor parte del incremento del bienestar económico que se estima tendría un valor actual de casi 10000 millones de dólares de 1992 [aproximadamente el 45\% del PIB mundial de ese año]. [...] La proporción del gasto militar de los países industriales se mantuvo alrededor del $75 \%$ del total mundial, mientras en los países en desarrollo pasó del 17 al $20 \%$, al reducirse la de que cesara la lucha por la supremacía nuclear que en un tiempo se consideraba pieza fundamental de la estrategia de disuasión en el conflicto Este-Oeste- por razones económicas: el empleo y el desempleo, cuyas tendencias se modifican por la revolución tecnológica que ha hecho descender la tasa de empleo y crecer la del desempleo, especialmente en trabajo no calificado, por ejemplo en Estados Unidos.

Debe tomarse en cuenta que hay un cúmulo de problemas generados por la concentración y centralización de capitales, así como por las tendencias especulativas del capital financiero, los cuales se han traducido en la contracción de los mercados de bienes. Es claro que por el crecimiento de la tasa de valor agregado, las cifras sobre comercio reflejan una situación de optimismo que no se expresa en un auge de los considerados mercados emergentes. La creciente competencia entre individuos, empresas, regiones y países, se aprecia también en las rivalidades étnicas o religiosas, las que ya se han manifestado en el desmembramiento de países, como Yugoslavia, Checoslovaquia y la Unión Soviética. En el mapa político del mundo, por tales razones, aún nos aguardan sorpresas.

También está presente la discriminación contra las minorías nacionales en algunos países, pero es en los desarrollados donde presentan el carácter más acentuado y ten-

los países en transición -excluída la ex URSS-". Cf. ibidem, p. 117. Las proyecciones: todos los países van a reducir su gasto militar de 1992 a 1998, según el FMI. Sin embargo, según cifras del SIPRI Yearbook, de 1995, en Israel, por ejemplo, el gasto en defensa aumentó de 20546 millones de dólares en 1994, a 25297 millones, en 1995. En Estados Unidos descenderá de 6\% a menos de 4\% del PIB de 1990 a 1998, afirmó el FMI en 1993. Sin embargo, en 1995 disminuyó sólo $3.5 \%$ respecto al año anterior, de acuerdo con cifras de World Arms and Disarmament. SIPRI Yearbook, de 1996. 
dencias deletéreas, fenómeno que ha sido canalizado por las ideologías dominantes. En efecto, como consecuencia de las tendencias del aparato productivo mundial, siempre bajo la ley interna de la creciente composición orgánica de capital que se traduce en incapacidad creciente para emplear a la población en la fase más productiva de su vida, se genera temor generalizado, delincuencia e inestabilidad política ante las escasas oportunidades que se abren para dar trabajo formal a las nuevas generaciones.

Ello a su vez se manifiesta en el resurgimiento del subempleo, que desde hace algunos años ha causado el aumento del sector informal de la economía. Pero la pérdida del empleo o, peor aún, las pocas posibilidades de encontrar un puesto de trabajo, se convierte en caldo de cultivo para la desesperanza, el malestar, la pérdida de valores y de objetivos en la vida de millones de jóvenes, quienes están buscando refugio en el mundo de las drogas o en el del alcoholismo o bien en la delincuencia, creando directa o indirectamente el conocido clima de violencia social que azota en especial a los países de Africa y América Latina.

Otro de los grandes problemas que preocupan a los habitantes del planeta en su fracción más desfavorecida es su lucha cotidiana por no morir de hambre o a consecuencia de enfermedades que bien podrían evitarse de haber las condiciones políticas favorables para revertir la tendencia a abandonar el Estado de bienestar o welfare state. ${ }^{4}$. Otros seres humanos luchan a diario porque se les den oportunidades de educación como medio para salir de su pe-

4 Ello incluso hasta en Estados Unidos, donde los resultados de una orden legislativa de 1985 para abordar los recortes presupuestarios más bien gravitan sobre el welfare state; en cambio, permiten recortes insignificantes en el presupuesto de defensa, según muestra Margot Sotomayor Valencia en este volumen. nuria; sin embargo, no es fácil que las obtengan, dado que en escala mundial se observa una contradicción de los recursos destinados a la educación pública.

En todo el mundo va creciendo lentamente la toma de conciencia respecto al cada vez más apremiante problema de la destrucción del ambiente. Lo grave de este asunto radica en lo poco que han hecho y hacen gobiernos y empresas para disminuir la contaminación del aire, los suelos y los cuerpos de agua.

En suma, muchos de los problemas que abruman a la especie humana, de los cuales se ha hecho rápido recuento, pueden incluirse en el marco de un fenómeno que genéricamente comprende todas estas manifestaciones sociales, económicas y políticas, generalmente conocido como crisis mundial o, si se prefiere, crisis de la civilización moderna, en la que la lucha por el mejoramiento de los instrumentos de exterminio representa una parte muy significativa todavía en la posguerra fría.

La carrera armamentista ha requerido de colosales esfuerzos que durante casi 50 años han absorbido vastos recursos humanos $y$ financieros. En ninguna otra etapa de la existencia de la vida humana se ha realizado un esfuerzo tan prolongado y costoso, ni empleado a tantos científicos y técnicos, como en la época de la guerra fría y en lo que va de la década actual. ${ }^{5}$ Asimismo, en ninguna otra época en la historia de la humanidad se ha dado tan impresionante $y$ dramática elevación de la capacidad de

5. Pese a los recortes al gasto en investigación y desarrollo (ID) para la defensa en Estados Unidos entre 1990-1994, periodo en que disminuyeron en 1996 la tasa respecto a 1995 fue de $4.3 \%$ y su proporción del gasto federal en ID, fue de $37.5 \%$. Véase Battelle, $R \& D$ Forecast Level, Columbus Ohio, 1994 y 1997. 
destrucción como es la que comprende desde el decenio de los cuarenta hasta nuestros días.

En la fase inicial de la posguerra fría se llegó a pensar que ahora sí se podrían usar los escasos recursos disponibles para satisfacer las necesidades acuciantes que han afectado a vastas proporciones de la población humana; ello debido a la creencia de que poco a poco irían disminuyendo los gastos con fines militares. Si bien es cierto que en el caso de la otrora Unión Soviética la reducción ha sido significativa hasta $1997,{ }^{6}$ ello se ha debido más por la desarticulación económica y política en toda Rusia y las otras repúblicas de la Comunidad de Estados Independientes (CEI) que por razones geopolíticas. En efecto, los cortes en los montos anuales destinados a fines de defensa por Estados Unidos, el Reino Unido y Francia han sido de escasa magnitud. En los casos de China, Japón y Alemania, dichos gastos han aumentado. Por ello nos atrevemos a afirmar que desde hace 50 años la lucha por el poder y la hegemonía en escala mundial se va convirtiendo en una creciente amenaza para la capacidad de supervivencia de la humanidad, superior tal vez a la que supone el ataque continuo al ambiente que entraña el calentamiento del planeta a causa de la combustión fósil y del efecto invernadero así generado, que acaso es irreversible.

La lucha por el poder es el elemento central de la acción política y los millones de personas que actúan como entes políticos per se no representarán un peligro para la

6. Debido al supuesto proceso de conversión industrial y a los compromisos asumidos en las Conversaciones sobre Eliminación de Armas Estratégicas (START) bilaterales entre la ex URSS y Estados Unidos. Sin embargo, después del desmantelamiento de los proyectiles de largo alcance aún quedan más de 4000 ojivas nucleares en la aviación estratégica, en submarinos nucleares o en bases terrestres de lanzamiento de misiles. supervivencia de los seres humanos. Pero lo detentadores del enorme poder militar si lo serán mientras tengan en sus manos un poder de destrucción de tal magnitud que no sólo pone en peligro de extinción a sus rivales políticos, sino la subsistencia de todos aquellos no involucrados en las pugnas por el poder.

De facto, no sólo la acción política de los grupos de poder de las grandes potencias, en su lucha competitiva y rivalidad en los distintos órdenes señalados, pueden poner en peligro la supervivencia humana; pueden hacerlo simplemente con las hambrunas, el deterioro de los suelos cultivables, la desforestación y el efecto invernadero, con sus efectos conocidos de cambios climáticos y caída de la producción de granos básicos. Además, podemos afirmar que en la medida en que las potencias tienen capacidad de destrucción con el poder nuclear que transportan sus vehículos estratégicos de lanzamiento y ataque, así como con las armas químicas, biológicas y otras incluso convencionales, aquélla será utilizada y no sabemos si sólo como medida de disuasión o específicamente en la búsqueda de hegemonía poniendo en entredicho la capacidad económica del sistema mundial para enfrentar el riesgo de catástrofe ecológica: esto involucra una comprobada guerra psicológica en curso.

Es pertinente recordar que el desarrollo desmesurado del potencial destructivo que las grandes potencias han alcanzado, en realidad no se origina con la guerra fría; empieza antes la segunda guerra mundial, con la rivalidad política y militar de las potencias del Eje: Alemania, Japón e Italia, de un lado, y del otro las potencias aliadas: Estados Unidos, la Unión Soviética, el Reino Unido y Francia. Esta rivalidad todavía no se ha reproducido a los niveles que existían antes de aquella conflagración. La producción acelerada por parte de Estados Unidos de la primera bomba atómica con su proyecto 
Manhattan tuvo como sustento la contienda entre estos dos bloques de poder, que posteriormente fue impulsada a los niveles que conocemos.

Hasta antes de la invención de la bomba atómica y por poderosas que fueran las disputas de las potencias por la hegemonía mundial, y por terribles que fueran sus armas, ninguno de esos conflictos ponía en peligro la subsistencia de la humanidad por la elemental razón de que el desarrollo de su capacidad destructiva no había llegado al nivel que se alcanzó con la invención de la bomba atómica y después con la de hidrógeno. $^{7}$

Se había dado paso a una nueva etapa histórica: de ese momento en adelante cualquier disputa por la hegemonía mundial estaría preñada de peligros para la subsistencia humana: $a$ ] con la bomba termonuclear y su capacidad de causar lo que desde 1989 se llamó invierno nuclear, y $b$ ] con otras armas de exterminio masivo (de las que nos ocuparemos brevemente más adelante), esos riesgos se han ido inventando nuevos instrumentos de destrucción en el área convencional.

Para la humanidad entera el invento y la utilización de la bomba significaron el comienzo de la era del terror atómico, ya que los más espectaculares avances en la capacidad de exterminio se realizaron en el periodo de la guerra fría, con el desencadenamiento de la intensa lucha de la URSS para romper el poder nuclear alcanzado y monopolizado por Estados Unidos en la segunda mitad del decenio de los cuarenta. Con lo anterior y desde esa década en adelante, el elemento decisivo en el desarrollo de la

7 Antes de 1953 la capacidad explosiva de la bomba atómica se media en kilotones -miles de toneladas de trinitrotolueno (TNT)-, pero con la temonuclear o de hidrógeno se llegó a los megatones (millones de toneladas de TNT). investigación científico-militar fue la rivalidad entre las dos superpotencias: Estados Unidos y la que hasta 1991 fue la URSS, rivalidad de un tipo que paradójica y trágicamente parece estar haciendo falta hoy día a las potencias occidentales cuando integran en la nueva OTAN a tres países de Europa central: Checoslovaquia, Hungría y Polonia, pero no Rusia. $^{8}$

Recapitulando, antes de 1991, concomitantemente a esa rivalidad, se había desarrollado la capacidad destructiva nuclear de mayor poder, a J con la bomba de hidrógeno; b] con la bomba de neutrones cuya fabricación fue finalmente prohibida y por consiguiente suspendida; $c$ ] con los sistemas de control y transportación de esos artefactos de la muerte, como es la aviación estratégica, los submarinos (SLBM) y los vehículos en tierra, o los emplazamientos de misiles de largo y de medio alcance (estos últimos producidos también por sus émulos en el Oriente Medio). ${ }^{9}$ Junto a todo ello se avan-

8. Anuncia peligros para la paz mundial que en 1997 la OTAN y en primer lugar Estados Unidos haya excluido a Rusia. Ello mientras, que por otra parte, una nación también euroasiática como Turquía permanece en la alianza. En el concepto de un historiador; en 1952, cuando se creo la OTAN "por una decisión tomada en Washington, el mapa político de Europa fue hecho de nuevo. Turquía quedaba dentro y Rusia fuera". Richard J. Barnet, The Alliance. America, Europe, Japan, the makers of the Postwar World, Nueva York, Simon and Shuster, 1984, p.345. Este peligro de una nueva rivalidad político-militar del calibre que tuvo la confrontación Este-Oeste, podría reproducirse con variantes. Allí están las armas y la revolución tecnológica a su servicio, a menos que la exclusión de Rusia de la OTAN que Occidente teme o acaso desea el regreso del comunismo a ese país, para armar de nuevo el equilibrio del terror.

0 9. Israel posee el misil Jericó, arma de nuevo alcance, pero estratégica para esa zona, que puede usarse con carga nuclear. 'Aunque este país no ha reconocido su posesión de tecnología nuclear, los hechos, ya históricos, hablan de que Estados Unidos se la proporcionó. Véase SIPRI Yearbook 1988. 
zaba en la creación de otras formas de destrucción, como las armas químicas y

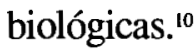

En la lucha por la hegemonía mundial y en paralelo con el enorme desarrollo de la microelectrónica la carrera armamentista ha tomado un nuevo giro y elevado su peligrosidad. Es el caso de las nuevas armas para posibles y futuros conflictos, que se usarían en guerras cibernéticas. En este terreno es donde hoy está logrando los más espectaculares avances la investigación científicomilitar.

En las líneas que siguen se hará un examen muy breve de los avances en la producción de nuevos y cada vez más peligrosos instrumentos de la muerte, en la hipótesis de que son las condiciones económicas y políticas los elementos centrales que influyen en el decurso que directa e indirectamente impulsan a los seres humanos a utilizarlos; ello en condiciones en que la globalización rinde crecientemente situaciones contradictorias y dentro de las que destaca en forma sobresaliente la disputa por el poder y la hegemonía mundiales. ${ }^{11}$

\section{LA ERA DE LAS ARMAS TERMONUCLEARES}

Es con la invención de la bomba atómica y su lanzamiento desde bombarderos de Estados Unidos sobre grupos hu-

10. Al respecto véase Margot Sotomayor Valencia, "Fin a la fabricación de armas de exterminio masivo", en México Internacional, México, diciembre de 1990.

11. Hemos expresado en otras ocasiones que existen: "1. Una guerra comercial que se manifiesta en la creciente presión para abrir las fronteras de los países proteccionistas e invadirlos de mercancías sobrantes. 2 . Una guerra científicotecnológica como parte de una estrategia comercial que permita mayores ventajas en la producción. Se busca así, con apoyo en la Revolución Científico-Tecnológica, la superioridad en la manos en 1945, en Hiroshima y Nagasaki, que se inició la era del terror atómico de la cual no hemos salido y que, contrario-sensu de lo que la razón dictaría, determina que el peligro de exterminio de la especie humana aumente no obstante haber concluido la guerra fría. El perfeccionamiento de dicho poder destructivo no terminó con su más notable fase: el arma termonuclear que supone no sólo la aplicación de la fisión nuclear sino de la fusión, que hace posible explosiones miles de veces más destructivas.

Como es ampliamente conocido, en el periodo que cubre la guerra fría (19451991), las dos superpotencias del orbe, la URSS y Estados Unidos se engarzaron en una competencia cada vez más exacerbada para avanzar lo más rápidamente posible en la producción de armas crecientemente efectivas para matar seres humanos.Ambas superpotencias no se trabaron en esta lucha solas, sino que se les unieron el Reino Unido, Francia y China. Con ello se formaría el llamado club de potencias nucleares, del Consejo de Seguridad de la ONU, como señalamos. Posteriormente se añadiría en el mismo propósito la India, país al que puede considerarse como el socio menor del mencionado club, dado que su desarrollo nuclear es insignificante comparativamente.

Se puede señalar que hay dos grandes tendencias en la geopolítica internacional por la disputa del poder nuclear. La primera, que es la dominante, consiste en que el club de potencias nucleares se ha puesto de acuer-

competencia comercial. 3. Una guerra financiera con devaluaciones y subvaluaciones de monedas para abaratar exportaciones, ofrecer créditos condicionados, generar quiebras en las bolsas de valores, fusiones de empresas y bancarrota de bancos. "Ver Arturo Bonilla, varios artículos en Problemas del Desarrollo, IIEC UNAM. Citado en Juan Carlos Mendoza, "México y la guerra económica de fin de milenio", en México Internacional, año 2, núm. 20, abril de 1991. 
do para impedir la proliferación de las armas atómicas. El derecho a la posesión de estas armas de exterminio masivo quedaría exclusivamente en manos de aquellos países que poseen poder nuclear: los gobiernos de las grandes potencias. El Tratado de No Proliferación Nuclear (TNPN) durante muchos años estableció en los hechos que ningún otro país podía aspirar a la posesión de esas armas; hoy día ordena también en los hechos que ninguna nación puede modernizar su arsenal nuclear: se trata, cuando más, de impedir las pruebas atómicas para salvaguardar la atmósfera terrestre.

La segunda tendencia que está presente en la lucha por la hegemonía mundial está caracterizada por los intentos y avances, no declarados públicamente, de algunos estados que para romper el oligopolio de las potencias nucleares realizan investigación para contar con ese armamento. Son varios los estados que han sido señalados, a veces erróneamente, como deseosos de poseer el poder nuclear. Así, es seguro que Israel, según algunos testimonios, ya posee la tecnología, mientras que Sudáfrica y Pakistán todavía no. Los tres niegan poseerla. ${ }^{12}$

En cada uno de los últimos países mencionados está fuera de toda duda que no aspiran a disputar el poder y la hegemonía mundiales; su actual potencial económico, científico y técnico, si acaso, les permitiría participar en el club de potencias nucleares, pero como socios menores, como es el caso de la India, cuyas explosiones subterráneas pueden ser pruebas con fines pacíficos. En realidad son las condiciones políticas regionales las que determinan y hasta cierto punto han permitido o impulsado el objetivo de convertirse en potencias nucleares meno-

12. Es sabido que el artefacto que explotó en Sudáfrica era en realidad de Israel. En el caso de Pakistán, el gobierno ha declarado que su tecnología nuclear está destinada a fines civiles. res. Por ejemplo, en el caso de Israel su presunto desarrollo nuclear será utilizado para disuadir posibles agresiones de sus vecinos islámicos. En el de Pakistán aquél se lleva a cabo por sus viejas disputas con la India, que ya posee la bomba atómica, no la termonuclear. La situación de Corea del Norte es particularmente difícil, pues podría sufrir el ataque de los misiles instalados en la parte sur de la península por el Departamento de Defensa de Estados Unidos. ${ }^{13}$

Los sucesivos gobiernos estadounidenses han demostrado una persistente hostilidad hacia Corea del Norte, atribuyéndole a ese pequeño país la capacidad de producir armas nucleares, asistido por tecnología de China, no obstante estar ubicado a miles de kilómetros del territorio estadounidense.

En discusiones preliminares entre los gobiernos de Corea del Norte y de Estados Unidos, este país ofreció desmantelar sus instalaciones nucleares en el sur de la península coreana a cambio de que la República Popular Democrática de Corea accediera a que inspectores de la Agencia Internacional de la Energía Atómica supervisaran las instalaciones nucleares de ese país. Al ocurrir esto, el resultado fue que Estados Unidos suministrará a Corea del Norte tecnología nuclear para usos pacíficos.

13. Esas instalaciones nucleares, situadas en una de las bases estadounidenses en Corea del Sur, se desmantelaron como parte de un plan de paz para reducir el gasto militar de Estados Unidos, por una parte, y por otra parte crear instalaciones con otros servicios que hagan creíble la disposición de los gobiernos -incluido el subcoreano- a dar prioridad a la apertura de mercados en escala global y a crear entornos ecológicamente viables en Asia, sobre todo a raíz de que Francia realizó unos ensayos nucleares en el archipiélago de Muroroa, en el Pacífico Sur, que suscitaron rechazo en la población de las islas cercanas. 


\section{LA CONCENTRACIÓN DEL PODER NUCLEAR}

Un indicador muy revelador de las grandes diferencias en la concentración del poder nuclear es el número de pruebas efectuadas por las potencias nucleares desde 1945 hasta 1994 (véase el cuadro).

\section{Pruebas nucleares realizadas, por país, 1945-1994 \\ (Explosiones aéreas y subterráneas)}

\begin{tabular}{lc}
\hline \multicolumn{1}{c}{ Países } & Pruebas $^{I}$ \\
\hline Estados Unidos & 1030 \\
Unión Soviética & 715 \\
ReinoUnido & 45 \\
Francia & 192 \\
China & 41 \\
Tơal & $2036^{2}$ \\
\hline
\end{tabular}

1.Para comprobar los avances en la investigación científica nuclear se requiere la realización incesante de pruebas.

2.Este total, se advierte en la fuente, incluye además 12 pruebas francesas sin determinación de fechas. También se adiciona una prueba subterránea efectuada por la India en mayo de 1974. FUENTE: The Bulletin of the Atomic Scientist, mayo-junio de 1995.

Como se aprecia en el cuadro, el mayor poder nuclear corresponde a Estados Unidos y la antigua Unión Soviética. Ambas potencias concentraron el $85.7 \%$ de las 2036 pruebas atómicas realizadas en todo el mundo desde que se decidió el potencial uso militar de la energía nuclear. La suma de las pruebas atómicas realizadas por las otras tres potencias nucleares es de $14.3 \%$. Esto es, Francia, con $10.1 \%$; Reino Unido, con $2.2 \%$, y China, con $2 \%$. Las diferencias entre las dos superpotencias (Estados Unidos y la URSS) y los otros miembros menores del club nuclear son abismales y es muy difícil que en el futuro cercano éstos últimos lleguen a igualar el poderío de las primeras en este terreno, máxime si se toma en cuenta el enorme costo financiero y social que entraña una carrera de ese tipo. Pero además, en la década de los noventa, con la casi culminación de la guerra fría, no es fácil que los gobiernos de las potencias nucleares menores, como Francia, el Reino Unido, China y la India, encuentren justificación política para la realización de más pruebas nucleares.

En efecto, así ocurrió en 1995, en que se desató una ola de indignación y de protestas en distintas partes del planeta contra Francia y China, cuyos gobiernos tomaron la decisión, cada uno por su lado, de hacer nuevas pruebas. Francia en el atolón de Mururoa, en el Pacífico Sur, y China en los campos de prueba de Lop Nor, dentro de su propio territorio. Lo importante es, y hay que destacarlo, que no obstante la oposición a dichas pruebas, éstas tuvieron lugar. Es más el Departamento de Defensa de Estados Unidos, pese a la enorme ventaja que posee frente a este poder nuclear menor, señaló la necesidad de llevar a efecto nuevas pruebas, ante el hecho públicamente expresado de que Francia y China habían violado el TNPN. De allí que surgiera la necesidad de revisar este Tratado y someterlo nuevamente a consenso, lo que fue un éxito. Ante la posible falta de apoyo político para la pruebas nucleares, y ante la necesidad de realizarlas para verificar la eficacia de los nuevos artefactos de muerte, en el Departamento de Defensa de Estados Unidos se ha proyectado disminuir su tamaño a efecto de que al detonarlos pasen inadvertidos para los detectores de pruebas nucleares. ${ }^{14}$

14. Esta miniaturización ya se llevaba a cabo, como un alarde de modernización, desde fines de los años sesenta, obedeciendo a la necesidad de estimular la demanda y aumentar el empleo en el sector civil, en el afán de perseguir el efecto spin off o derrama económica, lo que no se logró como solía ocurrir en los años treinta y cuarenta: en los años sesenta "la naturaleza de los productos mi- 
Pero si bien la parte más espectacular y tétrica de este escenario mundial corre a cargo de la producción, primero de las bombas atómicas, después de las termonucleares, todavía más poderosas y tembles que las primeras, no se puede considerar que en el proceso de escalamiento de la producción de medios de destrucción no se haya avanzado en otras vertientes.

\section{LA CARRERA DEL ESPACIO Y LOS MISILES}

El lanzamiento de bombas termonucleares exigía el mejoramiento de los medios para su transportación. En efecto, poco a poco se avanzó en los diseños para la producción de aviones más poderosos en capacidad de carga y autonomía de vuelo, lo que amplió su radio de acción. Asımısmo se fue desarrollando en escala nunca antes vista la producción de misiles cada vez más poderosos y eficaces, los llamados estratégicos, capaces de transportar ojivas nucleares cada vez más grandes, a mayor velocidad y a distancias mayores.

Históricamente la competencia entre las dos superpotencias se exacerbó con el exitoso lanzamiento del primer satélite soviético el 4 de octubre de 1957. Ello tuvo un gran impacto en la opinión publica de Estados Unidos y del resto del mundo, pues los medios de comunicación habían creado

litares y sus condiciones de fabricación hacían aún más ilusoria su capacidad de estımular la demanda y aumentar el empleo. Los gastos se orientaron hacia la tecnología de punta y a la investigación-desarrollo más que a la produccion en masa y la tendencia fue -entre otras- hacia la miniaturización (atómica-nuclear; bombarderos, misiles). Estudios recientes y reiterativos confirman la ausencia de una relación positıva entre gasto militar y empleo. Véase Michel Rogalski, "De las bondades del gasto militar a 10 dividendos de paz", en Problemas del Desarrollo, México, IIEC-UNAM, Vol. XXIV, enero-marzo de 1993. el convencimiento no sólo de que no había quien le disputara a este país la conquista del espacio, sino además de su superiondad militar. Incluso el gobierno de John F. Kennedy no cejó en su propósito de devolver a los estadounidenses la tranquilidad de que seguían siendo invencibles no sólo por su capacidad para librar una guerra de contrainsurgencia, sino también por su superioridad estratégica nuclear y que de ello tomaran nota los gobiernos y pueblos de todo el mundo.

Para proseguir con ese objetivo geopolítico, ya en la administración de Nixon se consideró necesario emprender el ambicioso proyecto de colocar al primer astronauta estadounidense en la luna en 1969.

\section{LAS ARMAS QUÍMICAS}

La carrera militar también avanzó en otros aspectos no menos peligrosos y terriblemente destructivos, como la producción de armas químicas y bacteriológicas. Sobre ellas poco se dice y la opınıon pública internacional está muy mal informada de los riesgos que se corren ante un descontrol durante el manejo o almacenamiento de ese tipo de armas o de las consecuencias sobre la población ante el posible uso de las mismas.

En el caso de las armas químicas se sabe que el ejército estadounidense las utilizó, por ejemplo, en la guerra de Vietnam, en acciones de defoliación de las selvas con el llamado agente naranja. También que se lanzaron contra algunos núcleos de la población vietnamita, pese a que, según los propios estrategas militares, ella entrañaba un peligro para los movimientos postenores de las propias tropas estadounidenses.

El gobierno de Vietnan llevó a efecto estudios prolongados (desde la conclusión 
del conflicto en 1975, hasta nuestros días) para medir y analizar tanto, las secuelas que las armas químicas han dejado sobre las víctimas, como para evaluar la intensidad de los daños que dichas armas provocaron en las selvas, suelos, cultivos, fauna y cuerpos de agua. Los trabajos al respecto no son concluyentes, pero de lo que se ha investigado hasta ahora se sabe que los efectos son terribles y casi incalculables.

El otro caso de utilización de armas químicas que apenas se conoce se dio durante la guerra que por ocho años sostuvieron Irán e Irak en la década de los años ochenta. El gobierno iraní denunció en la ONU al gobierno y el ejército de Irak por el hecho de haber estado utilizando dichas armas contra supuestos o reales objetivos militares. ${ }^{15}$

En 1995 el gobierno de Irak fue nuevamente denunciado ante la opinión pública internacional por emplear armas químicas en la guerra que ha librado en contra de los kurdos que viven en la parte norte de ese país. No se puede descartar que estas denuncias sean ciertas, pero también es necesario señalar que la prensa occidental ha recurrido en buena medida al amarillismo periodístico debido a que se considera a Saddan Hussein como un objetivo militar para Estados Unidos, pues el ejército turco _cuyo gobierno forma parte de la OTAN _ es responsable de muchas de las atrocidades sufridas por los kurdos que viven en turquía, las que en buena medida fueron pasadas por alto por la ONU.

\section{LAS ARMAS BACTERIOLÓGICAS}

En lo que se refiere a las armas de tipo bacteriológico, se puede afirmar que son

15. Véase Arturo Bonilla, "El petróleo y la guerra Irán-Irak", en Problemas del Desarrollo, México, IIEC-UNAM, vol. XXI, núm. 82, julioseptiembre de 1990. de las que actualmente tiene menos información la ciudadanía de todos los países del mundo. Seguramente el secreto que se mantiene al respecto obedece al enorme y devastador impacto que produciría en la opinión pública internacional el conocimiento de los hechos y que la llevaría a luchar contra la investigación, producción y utilización de tales armas ante un solo hecho crucial: las armas bacteriológicas afectarían directamente a los seres humanos, sin que el agresor pueda distinguir entre objetivos militares y civiles.

A este respecto se puede afirmar que no hay ninguna garantía de que el arma bacteriológica dañe exclusivamente al personal militar; pues con toda seguridad sus efectos perniciosos se extenderían a la población civil. Aún más, tampoco hay seguridad alguna de que los efectos de las armas bacteriológicas se constriñan al territorio del país enemigo. Cabe pensar que también se vieran afectados núcleos de población de las naciones vecinas o aun no tan cercanas; incluida la del país que haya empleado las armas bacteriológicas.

La resistencia en contra de ese tipo de armas seguramente aumentaría si se llegara a conocer cabalmente el alcance de los efectos biológicos de los distintos tipos de virus ya sea en el ámbito geográfico, ya en los niveles de mortandad que provocarían, o los daños temporales o definitivos que causarían en la salud de los sobrevivientes. Tampoco se sabe cuál sería su duración en el ambiente, o sus efectos "laterales" en suelos, aire, agua, flora y fauna. También se ignoran las magnitudes producidas de los distintos tipos y más aún la forma en que se resguardan y de los riesgos que se corren en tiempos de paz ante posibles fallas de control.

Por todo lo anterior se pueden comprender las causas por las que se mantiene en secreto el monto de los recursos 
financieros que en el mediano plazo se destinarán a tales armas. Así también el número de los científicos que estudian procedimientos crecientemente más eficaces para que -por medio de virus- se puedan fácilmente exterminar más seres humanos. A este respecto hace falta una muy fuerte presión social orientada a suspender todo tipo de investigaciones de esta naturaleza. Más aún si, como ocurre en otros campos de la investigación científica, sus resultados más bien pueden orientarse a mejorar la salud humana y el bienestar colectivo, como sucede con los descubrimientos de la ciencia básica.

\section{LAS ARMAS CONVENCIONALES}

En la era termonuclear el desarrollo de las armas químicas y bacteriológicas ha continuado hasta el presente, aunque, como se señaló, en los años noventa Estados Unidos destinó un menor flujo de fondos federales a la investigación científica y sus aplicaciones tecnológicas, las cuales también se orientan a mejorar las armas convencionales, tanto las llamadas cortas como las largas, cuya comercialización ha aumentado su importancia en Estados Unidos y en Rusia, que han sido los mayores exportadores de armas pesadas a las regiones del llamado Sur. En este rubro tampoco se ha detenido la carrera armamentista, puesto que el mercado es muy amplio, pese a que en América Latina estuvo restringido por 20 años el envío de armas. Sin exageración se puede afirmar que ha habido un aceleramiento en el "progreso" de este tipo de armamento. Los muy variados conflictos que ha habido en la era del terror nuclear, es decir, durante el periodo de la guerra fría, pero también después de ella debido a varias causas, dan cuenta fehaciente de su vigencia. Ello a pesar de que con los auspicios de la Organización No Gubernamental en el Comité del Desarme se ha trabajado intensamente en la creación de zonas desnuclearizadas en diversas regiones del mundo. Es preciso recordar que fue en México donde se llevó a cabo la firma del Tratado de Tlatelolco, ya en 1968, para la proscripción de armas nucleares en América Latina. También en Asia Pacífico se creó una zona libre de armas nucleares con el Tratado de Rarotonga y actualmente se trabaja en la creación de otra zona semejante en el Medio y el Cercano Oriente, donde su necesidad es urgente.

El incesante mejoramiento y ampliación cada vez mayor en las variedades de armas convencionales se explica principalmente porque tienen la "ventaja" de que al usarse no ponen en peligro de exterminio a otros grupos humanos fuera del área del o de los conflictos, al contrario de las armas de exterminio masivo, que pueden afectar a poblaciones de grandes áreas geográficas.

En el caso de las armas cortas se ha ampliado su variedad y velocidad, disminuido su peso y acrecentado su potencia de fuego y alcance. Desde el revólver, pasando por las ametralladoras, hasta las granadas, los morteros, los lanzallamas, las bazucas y otras. Se ha aplicado la óptica para las mirillas que cuentan con rayos infrarrojos para detectar el calor que despiden los seres vivientes. También hay que señalar el apoyo que brinda la electrónica para elaborar un mayor número de dispositivos que sirvan para controlar explosiones en aire, tierra o agua, sean éstas instantáneas, retardadas o en un tiempo predeterminado mediante mecanismos de relojería. Con la electrónica también es posible dirigir ataques a distancia mediante comandos interconstruidos. Además, continúa el avance sistemático hacia la miniaturización de las armas y de los explosivos, sin que por ello pierdan poder de fuego.

En las armas largas también se ha avanzado en una escala no igualada en los 
últimos cincuenta años. Así, se producen cañones de diversos tipos, con aceros más resistentes u otros materiales más ligeros pero capaces de soportar altas temperaturas, sin menoscabo de su mejoramiento tanto para alcanzar distancias mayores, como para aumentar la precisión de sus impactos gracias a la ayuda de medios electrónicos avanzados y de la óptica.

En el mejoramiento de los tanques de guerra también se ha avanzado enormemente, pues se cuenta ya con un prototipo de robotank, es decir, un vehículo que puede desplazarse sin tripulación. Para darle mayor capacidad de acción se le ha dotado de cañones con mayor poder de fuego y mayor precisión, gracias a nuevos aditamentos electrónicos. Se han construido otros prototipos de robotanques, capaces de disparar misiles tierra-tierra y tierra-aire.

Con todo el esfuerzo realizado en el mejoramiento de estos tipos de armas largas, no es precisamente en los cañones y tanques donde se aprecian los avances más espectaculares. En rigor éstos se han estado llevando a efecto en la producción de aviones militares y helicópteros. Del avión de hélice se pasó pronto al de turbohélice y al de reacción. En algunos casos se pasó directamente de la hélice al reactor.

De las innovaciones que se han logrado, verbigracia, en los aviones caza de uno o dos pilotos, llama la atención su cada vez mayor capacidad de maniobra a velocidades no imaginadas hace unas cuantas décadas. Los aviones de este tipo no sólo son capaces de volar a velocidades mayores que la del sonido, sino que están dotados de las versiones más modernas de misiles aire-aire o aire-tierra; pueden también efectuar incursiones de bombardeo. Para todo ello cuentan con avanzados instrumentos electrónicos y poderosas cámaras que les permiten realizar labores de reconocimiento y ubicación de instalaciones enemigas.

Se ha logrado disminuir la distancia de despegue y aterrizaje de los aviones caza que transportan los portaviones, e incluso los tecnólogos militares ingleses han construido uno capaz de despegar verticalmente, el Harrier.

Al final de la segunda guerra mundial el mundo se conmovió porque dos bombas atómicas se lanzaron sobre Japón. Las llamadas superfortalezas B-29 que las transportaron eran aviones de cuatro reactores, considerados en ese momento como la expresión militar de la tecnología de punta en la aviación moderna. Esas naves son ya piezas de museo, pues los aviones actuales cuentan con mayor capacidad de carga, más tiempo de vuelo (autonomía de vuelo) y mayor velocidad. Hay naves tan grandes que en ellas puede transportarse armamento pesado a grandes distancias en el curso de unas cuantas horas.

El helicóptero ha sido convertido en una poderosa arma de apoyo en las operaciones militares con armamento pesado ya sea en tierra o en el mar. Esto es, forma parte del equipo bélico pesado que en forma regular suele utilizarse en las guerras convencionales. Una de las principales ventajas del helicóptero sobre el resto del armamento pesado es su gran versatilidad, pues puede utilizarse en zonas en que es casi imposible o sumamente costoso y riesgoso llevar equipo bélico pesado. También se utiliza para operaciones de localización, persecución o rastreo de cuerpos guerrilleros _o movimientos civiles políticamente radicalizados_en las acciones bélicas y de inteligencia llamadas "guerras de baja intensidad". Asimismo se le utiliza en operaciones de despliegue rápido de tropas, en las que el factor sorpresa es determinante para el éxito de la acción, o en maniobras 
de rescate de heridos o muertos en zonas inaccesibles o incomunicadas. El helicóptero suele utilizarse también para la búsqueda y rescate de personal militar en los mares.

\section{LAS ARMAS CIBERNÉTICAS}

A lo largo del periodo de la guerra fría y como consecuencia de la rivalidad militar de las dos superpotencias, en Estados Unidos se fueron haciendo nuevos y poco conocidos artefactos de muerte, que según algunos observadores están destinados a la ciberguerra (cyberwar). Como si se tratara de novela de ciencia ficción, en la década de los noventa se ha avanzado lo suficiente para pensar que es factible desarrollar ese tipo de guerra, como si se olvidara que los medios de destrucción obtenidos en las décadas previas son lo suficientemente abundantes para destruir varias veces a toda la especie humana.

En efecto, desde hace unas tres décadas, probablemente, se inició la producción de un moderno armamento que, en relación con otro tipo de armas, se distingue por la creciente incorporación de los avances en la microelectrónica. ${ }^{16}$

Todo parece indicar que Estados Unidos realizó la primera guerra cibernética en el Golfo Pérsico, en contra de Irak. Desde los altos mandos de las fuerzas arma-

16. Al respecto, véase la reciente información periodística sobre unas maniobras militares en Estados Unidos (Agencia Reuter, Fuerte Irwin, EU, 28 de marzo): "Con equipos electrónicos por valor de más de 250 millones de dólares, una fuerza experimental de 7000 integrantes fue trasladada recientemente hasta el desierto de Mojave para luchar contra una fuerza "roja" equivalente, que invadía al mítico país aliado estadounidense de Mojavia. El secretariode Defensa, William Cohen, estuvo allí para ver en acción la nueva tecnología que se utilizará en las guerras del próximo siglo [...]'Hoy he visto el futuro del arte de la guerra', ha das estadounidenses y desde antes que se iniciara el conflicto contra el gobierno iraquí, se hablaba insistentemente de la posibilidad de que si se tomaba la decisión política de sacar a las tropas iraquíes de Kuwait, la guerra no duraría mucho. Los comandantes estadounidenses insistían en que el conflicto no sólo se ganaría, sino que además sería breve, con un bajo costo en el número de bajas de sus tropas ya que estimaban que el conflicto se podría resolver en el curso de tres a cinco días.

Hasta antes del comienzo de la guerra, todo parecía indicar que se trataba simplemente de configurar un escenario fantástico de poderío bélico con el que se trataba de tranquilizar a la opinión pública de Estados Unidos, o que se había emprendido una guerra psicológica para atemorizar al gobierno de Irak y sus posibles aliados, $o$ incluso que eran simples baladronadas (como si se tratara de juegos de guerra infantiles o la combinación de los tres factores señalados). Sin embargo, pese a que dicha guerra no la ganaron los generales en tres o cinco días, en buena medida tenían razón: sus declaraciones descansaban en la certidumbre, que muy pocos conocían, de que ya tenían a su disposición una serie de complejos aparatos microelectrónicos capaces de reducir en gran medida la duración de una guerra como la librada contra Irak, a cuyo ejército anularon e inter-

declarado ante los periodistas [...] Lo que ustedes ven aquí es una revolución de la forma en que se maneja la guerra [...] éste es el futuro y no hay marcha atrás.' [...] Un sargento le mostró a Cohen cómo, con sólo accionar el mecanismo del "ratón" de su computadora, podía dirigir un avión a reacción F-16 y el fuego de artillería contra un tanque enemigo al otro lado de una colina. En menos de 30 segundos, una imagen parecida a la de un juego de video, surge en la pantalla para mostrar la destrucción "(real) del objetivo". "La tecnología digital, lo nuevo en el arte de la guerra", Excelsior, 29 de marzo de 1997. 
firieron su medios de comunicación por radio, así como su sistema de telecomunicaciones.

Es evidente que, junto a todo lo anterior, se realizó un incesante bombardeo sobre objetivos militares en Irak con aviones equipados con computadoras que permitían a los pilotos localizarlos y destruirlos con gran precisión. Lomismo ocurrió con helicópteros y barcos.

\section{NUEVOS PROTOTIPOS DE ARMAS}

Si bien no se cuenta con un adecuado sistema de información pública sobre ciertos temas, a manera de ejemplo, los observadores han presentado los siguientes tipos de armas, sobre cuyo desarrollo existe gran incertidumbre:

Las armas radiológicas: son todas aquellas de tipo convencional que pueden cargarse con proyectiles a base de residuos nucleares, incluso con desechos de las plantas nucleoeléctricas, sin que lleguen a ser armas propiamente nucleares.

Las armas infrasónicas: sobre éstas existe un registro de las Naciones Unidas que data de los años ochenta. ${ }^{17}$

Respecto a las nuevas armas que a continuación se mencionan, todo indica que empezaron a desarrollarlas sobre todo, pero no exclusivamente, las grandes potencias. Estados Unidos y la URSS, a partir de la Iniciativa para la Defensa Estratégica, proyecto puesto en marcha en la década de los ochenta. Se trata de armas sobre las que hay un gran desconocimiento por parte de la opinión pública: ${ }^{18}$

17. ONU, Desarme, vol. 9, 1984, p.343.

18. La información se obtuvo de un científico militar, Carlos Portales, "La iniciativa de defensa estratégica y el cambio tecnológico", en Carlos Ominnani (coord.). La Tercera Revolución a) Las armas de haces de partículas: son artefactos para defender las instalaciones de silos que contienen y resguardan cohetes de todo tipo.

b] Las armas de haces de microondas: se trata de hacer prototipos para atacar misiles enemigos en vuelo.

c) Las armas de rayos laser (Light Amplifier by Stimulated Radiation Emission) son de varios tipos, clasificados como sigue: 1] laser químico para interceptar misiles, aviones y helicópteros; 2] laser de gas para interceptar misiles, aviones, helicóperos; 3 ] laser de "excimer", arma sobre la cual solo se encontró una referencia pero sin que se precisaran sus características, aunque el autor de la misma indica que se trata de un arma instalada en misiles emplazados en tierra con espejos en el espacio. También su propósito es el de interceptar misiles; 4] laser de electrones libres para intercepción de misiles, y 5] laser de rayor $X$ para el mismo propósito.

d) Las armas de energía cinética. Se avanza en su diseño para interceptar misiles.

Cada una de estas nuevas armas tiene ventajas y desventajas en la consecución de los objetivos para los que se les diseña. Es difícil saber cuáles han logrado mayor eficacia.

La lista de nuevas armas seguramente se podría extender; ya que muchas de ellas ahora sólo son del dominio de la investigación científica militar y de los estados mayores de las fuerzas armadas de las grandes potencias. No hay nada que nos permita pensar que la producción de nuevas armas se va a detener, pues los intereses del orden económico, social y político siguen estando enfocados al objetivo de avanzar en la

Industrial: impactos internacionales del actual viraje tecnológico. Rial, Anuario 1986, Buenos Aires, Grupo Editor Latinoamericano. 
supremacía mundial, o de evitar la pérdida de la posición que se ha alcanzado como potencia, ya que la estrategia de disuasión en su modalidad unilateral volvió a adquirir vigencia después de que la Unión Soviética se desintegró y perdió sentido la estrategia de disuasión nuclear recíproca -establecida desde 1967, cuando se tuvo la seguridad de que la URSS poseía la capacidad para dar un segundo golpe nuclear-, que constituyó un factor de mayor seguridad internacional $e$ hizo posible la distensión entonces y a lo largo de los años setenta hasta el advenimiento de la administración Reagan y después, cuando se pone a punto la llamada Guerra de las Galaxias (un sistema antimisiles muy controvertido) mediante un programa que finalmente se eliminó en 1995.

Para tener mayores elementos de análisis partiremos de la consideración de que la revolución científico-técnica se caracteriza por tener dos grandes vertientes en su desarrollo a lo largo de muchas décadas: a] la parte constructiva de la misma, en la que las innovaciones tecnológicas contribuyen al incremento de la producción de bienes de consumo y de producción, para a su vez aumentar la escala del producto, y $b$ J la parte convencionalmente considerada destructiva de dicha revolución científico-técnica, o sea la creación, por un lado, de medios más eficaces y de mayor capacidad de exterminio no sólo de seres humanos, sino también de otros organismos vivientes, $y$, por otro, de armas no letales, destructoras de objetivos diversos en calidad de blancos. En rigor, la modernización tiene por sí misma un efecto destructivo, como es conocido:

i] Sobre el capital existente, al ser desvalorizado por la vía de la obsolescencia. ${ }^{19}$

19.Hemos señalado que "mientras el capital trasnacional siga imponiendo su solución, tenderán a ocurrir graves fenómenos, todos ellos ii] Sobre el empleo, cuya creación se contrae respecto al modelo tecnológico precedente. Y si la modernización de las armas tiene un efecto potencialmente mucho más destructivo sobre el capital, con la vigencia del Estado nacional es probable que continúe por muchos decenios como instrumentos de poder; pero en contra del desarrollo capitalista con estabilidad, así como del ambiente y la vida humana.

Sin duda en el proceso de innovaciones tecnológicas hay una franja en que éstas pueden tener dos fines: o "constructivos" o "destructivos", dependiendo en gran medida de factores extracientíficos y extratecnológicos.

En realidad, esos factores exógenes a la revolución científico-técnica están determinados por las condiciones sociales, de las que destacan las relacionadas con la estructura del poder político, sobre todo si se trata de innovaciones militares con una orientación claramente destructiva: para defenderse de posibles agresiones y para disuadir $o$ atacar a un enemigo.

En el terreno de las innovaciones científico-tecnológicas para la producción civil, las decisiones están fuertemente determinadas no por factores de carácter

impulsados desde abajo, por la revolución científico-técnica hoy en manos de las fracciones más poderosas del capital: 1. El aumento de la sobreproducción. Conforme avanza más rápidamente la revolución científico-técnica y, en relación directa a sus avances cuando se aplica a la producción, se observa claramente un aceleramiento en la obsolescencia del capital, esto es, la aparición de nuevos equipos o máquinas que sustituyan a las que están en uso, sin que éstas logren concluir su vida productiva, al aparecer en el mercado nuevas máquinas con ventajas sobre las existentes. "Arturo Bonilla", "La crisis actual y la revolución científico-técnica", en Problemas del Desarrollo, vol XXI, núm. 80. México, IIECUNAM, enero-marzo de 1990. 
eminentemente político, sino por el espíritu de la ganancia, ya sea para acrecentarla, $o$ para conservar una posición en el mercado. El deseo de lucrar impulsa las decisiones orientadas a la búsqueda de innovaciones ya sea para disminuir los costos de los insumos, o para responder a demandas específicas del mercado.

La toma de decisiones respecto al rumbo que se dará a la investigación científica o tecnológica no sólo está determinada por los factores arriba señalados, sino también por el propio nivel del desarrollo de las investigaciones, el cual está determinado por el grado de avance y la naturaleza de las interrogantes científicas presentes en dicho nivel de desarrollo. Esto es, no se pueden resolver ni interrogantes ni proponer hipótesis que estén más allá de las posibilidades que se tengan en ese nivel del conocimiento.

En suma, la investigación científica y sus aplicaciones tecnológicas están fuertemente influidas por dos elementos cardinales: el entramado social en el que se desenvuelven y el nivel de desarrollo que hayan alcanzado las ciencias específicas en las que descanse y de donde parta la investigación.

Esos dos grandes factores son decisivos para saber a qué rubros de la investigación científica se les dará prioridad, para decidir por cuál camino avanzar en dichas transformaciones técnico-científicas, tanto durante el curso de las mismas como en la toma de decisiones respecto al cómo, cuándo y dónde utilizar los nuevos productos que se han generado.

De lo anterior parecería relativamente correcto el planteamiento de que el avance en el conocimiento científico es neutral. Ahora, la neutralidad en el avance del conocimiento científico atañe a sólo un aspecto del problema: el de suponer que dicho avance obedece solamente y en forma exclusiva al grado y nivel de desenvolvimiento de las ciencias. Este aspecto del problema es particularmente cierto, sobre todo en el desarrollo de las investigación en ciencias básicas. Sin embargo, aun en este caso hay factores políticos que favorecen 0 impiden su desenvolvimiento. Por ejemplo, el énfasis que se dio a dicha investigación, especialmente en la física, y que dio lugar a la creación de la bomba atómica, es una muestra de que, pese a todo, hasta las ciencias básicas se ven influidas por el contexto político y social en que se desarrolla la investigación. En lo que se refiere a las ciencias aplicadas, el término neutralidad dejó de ser exacto para calificar a dicha actividad, ya que no se puede hacer caso omiso de la existencia de condiciones políticas, de factores económicos y de carácter social en la decisión sobre que tipo de investigación realizar, cuándo y cómo.

En el planteamiento "neutralista" del desarrollo de la ciencia aplicada se debe reconocer que las aplicaciones tecnológicas de los nuevos inventos y descubrimientos no dependen de los científicos, sino de quienes toman las decisiones sobre su destino, es decir, por los integrantes de la estructura de poder establecido: en Estados Unidos y Francia, el Poder Legislativo en el Congreso, donde poseen influencia y clientelas los políticos y las cúpulas de los establecimientos militares: es el caso de la investigación militar y de sus aplicaciones necesariamente destructivas, aunque se destinen al servicio de la seguridad nacional del país en cuestión. Por ello se impone la pregunta que se hizo en 1992 Michel Rogalski, del Centro Internacional de Investigaciones sobre Ambiente y el Desarrollo de París: " ¿El capitalismo tiene una permanente necesidad de la guerra?"20

En el planteamiento de la neutralidad en las decisiones de financiamiento en el 
ámbito de las ciencias básicas, para sostener aquélla se hace caso omiso de los intereses privados a cuyo servicio está la instancia pública, la cual tiene el poder para contratar a determinados científicos y poner a su disposición los recursos financieros y la infraestructura necesaria para los proyectos de investigación. Ello aún siendo, como en Estados Unidos, fondos autorizados por el Congreso, ya sea para el Departamento de Defensa o de otras instituciones públicas consagradas a la investigación. Las personas que están en los círculos del poder económico o político son las que plantean qué tipo de investigaciones realizare influyen para que el Poder Legislativo las autorice.

20. Considera este autor que, en caso afirmativo, "la lucha por el desarme se sobrepone a la lucha contra el capitalismo, la crisis y la austeridad. En el caso negativo, los complejos militares industriales se desarrollan en contradicción con el resto de la sociedad. incluyendo a los sectores capitalistas civiles. Líneas de fractura van entonces a aparecer facilitando el aislamiento de estos complejos [...] Esto ha sido materia de debate durante muchos años en Francia, como en otros países, en donde lo que está subyacente es evidentemente la discusión sobre el efecto benéfico o no para la economía del gasto militar en países industriales; es decir, el keynesianismo militar [...] Fue justamente en torno a la cuestión de la incidencia tecnológica en la materia que se produjo durante los años ochenta el cambio más brusco en las posiciones. Este cambio afectó incluso a la alta esfera militar del Pentágono y no dejó de tener eco en Francia. Que revistas como Fortune ("More Spinoffs fron Defense", primavera-verano de 1991, pp. 60-65) a L'Usine Nouvelle (Jean Pierre Casanayou, "Recherche militaire: le mythe des retomées", L'Usine Nouvelle, 12 de enero de 1989, pp.28-33) se inquieten ante la debilidad de esta incidencia es síntoma del contagio de la preocupación en medios tradicionalmente favorables al gasto militar, Las tecnologías producidas por los programas militares de investigación son, por lo general, muy marcadas y su rápida aplicación al sector civil se encuentra frecuentemente trabada por condiciones restrictivas". Otro autor citado. Francois Chesnais, traza la evolución de este debate mostrando cómo "el gasto [militar] ha debilitado el tejido industrial
Una vez determinado qué es lo que se va a investigar y con qué fondos se dispone, las investigaciones se ponen en curso. Los altos funcionarios que están al frente de los laboratorios o de las instalaciones serán los responsables de la contratación de los científicos y de la marcha de aquéllas, en función de las disciplinas específicas con las que se trabaje. En el caso de investigaciones científicas y de sus posteriores aplicaciones tecnológicas con fines civiles opacíficos, esto es, directamente comerciales, la toma de decisiones queda a cargo de los dueños de las empresas o de los ejecutivos que las administran.

\section{LA POSGUERRA FRÍA Y CONTINUACIÓN DE LA REVOLUCIÓN CIENTÍFICO - TÉCNICA EN SU FASE DESTRUCTIVA}

Para la otrora URSS el fin de la guerra fría significaba desvincularse de la pesada carga financiera que la carrera armamentista y espacial significaba tanto para el conjunto de la estructura productiva soviética, como para el presupuesto del propio gobierno. Entre los factores que impulsaron su debilitamiento financiero, military político se encuentra su entrada en Afganistán, que gravitaba pesadamente sobre el presupuesto de ese conjunto de estados nacionales capitaneados relativamente por la Federación Rusa. ${ }^{21}$

No es de extrañar que en diciembre de 1988, a partir de que Mijail Gorvachov anunció en el seno de las ONU el retiro de fuerzas de tierra, se desataran en Europa Oriental una serie de acciones políticas centrífugas, de tal magnitud que en menos

llevando a los dirigentes del Pentágono a tomar conciencia de la incapacidad del sistema productivo americano de satisfacer sus exigencias tecnológicas, obligándolos así a dirigirse a los fabricantes japoneses". Francois Chesnais (coord.).Competitivé internacionales et depenses militaires, CPE/Económica, Paris, 1990, p.245, citado en Michael Rogalski, op.cit. 
de un año, en noviembre de 1989, la República Federal de Alemania se reunificaba con la República Democrática Alemana. Dos años después, el 25 de diciembre de 1991, Gorvachov perdía su empleo y desaparecía la Unión Soviética a consecuencia, ya no de las limitaciones del presupuesto soviético, sino de una verdadera eclosión social de distintas expresiones nacionalistas de los pueblos que sentían los excesivos rigores del centralismo político y económico, aunque no hay que subestimar las labores de la Agencia Central de Inteligencia (CIA), cuya participación en aquella ha sido desclasificada. Cierto es que en la estructura del Estado soviético se había desarrollado una enorme burocracia que como mal necesario se requería para poder centralizar el esfuerzo productivo de millones de personas a fin de ganarle tiempo al tiempo, es decir, a fin de alcanzar a las grandes potencias del mundo.

Como se sabe ampliamente, cuando los bolcheviques tomaron el poder en 1917, esto es, recién creada la Unión Soviética, el retraso científico y tecnológico de este vasto

21. El hecho político de mayor envergadura indicativo de lo anterior se dio en diciembre de 1988, cuando Mijail Gorvachov anunció en la ONU que la ahora ex Unión Soviética retiraría unilateralmente a 500000 soldados del Pacto de Varsovia, principalmente del territorio de la otrora República Democrática Alemana. Era unilateral porque la OTAN no retiraría fuerzas militares de sus bases en Europa sino hasta 1989-1990.

La primera decisión de 1988 fue magnificada por la prensa occidental que presentaba a Gorvachov como un pacifista verdadero. El mismo así se presentaba en los foros mundiales. Sin descartar los elementos subjetivos de este dirigente político, el problema sustancial que lo animaba era el rápido deterioro del presupuesto soviético que objetivamente impedía seguir en la carrera modernizadora militar; por otra parte estaba y está el hecho de que la ex Unión Soviética tenía una economía poco competitiva en la producción de bienes de consumo final y de demanda intermedia. conjunto de naciones era muy grande en comparación con las otras grandes potencias, intensamente interesadas en echar abajo ese nuevo experimento social que significó la revolución bolchevique. Dicho centralismo político obedecía a la imperiosa necesidad geopolítica que tenía la dirigencia soviética de centralizar al máximo una buena parte del excedente económico generado por el pueblo soviético para hacer frente a las necesidades de tipo militar que le imponía la carrera armamentista. Dicha centralización de recursos financieros se hacía tanto para defenderse de las potencias occidentales como para tratar de ganarles terreno en el aspecto político, militar, económico y científico-tecnológico. ${ }^{2}$

Estados Unidos también tuvo que pagar el alto costo de la competencia y rivalidad entre los dos bloques más poderosos del mundo. La sociedad estadounidense había quedado subsumida en un ambiente militarizado, del que por cierto todavía no sale, y sobre todo perdió parte de su supremacía hegemónica en el terreno económico, financiero y tecnológico.

Sus principales socios políticos en el curso del enfrentamiento anticomunista con

En efecto, para obtener divisas duras la URSS debía exportar principalmente petróleo, de donde obtenía entre 65 y $70 \%$ del total de sus divisas. Otro 10 a $20 \%$ se obtenía de la venta de armamento. Por ello la dirigencia soviética necesitaba desengarzarse de los compromisos políticos que internacionalmente desempeñaba como superpotencia.

22.Para Estados Unidos lo anterior significaba un triunfo de proporciones históricas, ya que sin disparar un solo tiro había logrado vencer a la potencia que era su mayor rival. Pero dicho triunfo histórico no significó que se hubiera incurrido en una política sin costos. Ellos fueron enormes y según un trabajo elaborado por personal militar de Estados Unidos, ascendían a la impresionante cifra de 3.5 billones de dólares desde 1945 hasta 1990. 
confrontación pasan a un segundo plano, pero de ninguna manera se pueden descartar. En el caso de Estados Unidos, la principal potencia militar del mundo, si bien avanza en el demantelamiento de las bases militares que rodearon a los países socialistas o de algunas otras que sólo tuvieron sentido por la confrontación Este-Oeste, o en la disminución del apoyo presupuestario que se daba a organismos como la CIA, también es cierto que no se ha dejado de poner el acento en la producción de armas nuevas, como las de tipo cibernético.

La guerra del Golfo Pérsico de 1991 fue posible, con las características que tuvo, debido a la política de reforzar la investigación científico-militar como condición necesaria aunque no suficiente para continuarla. La elite del poder estadounidense sabe perfectamente que no basta con la superioridad militar para mantener a Estados Unidos a la cabeza de la supremacía mundial. La administración de Clinton ha puesto un interés especial en lograr la supremacía en el terreno productivo, tratando de que las empresas estadounidenses vuelvan por sus fueros y desplacen a las de Japón y la Unión Europea. Los dirigentes de Estados Unidos harán lo máximo para que su país recupere lo perdido en la competencia y rivalidad comercial. Aunque el problema no es exclusivamente de voluntad.

En el caso de Federación Rusa se debe tomar en cuenta que aun cuando la Unión Soviética desapareció, no se ha perdido todo el poderío militar ruso, por más que se haya debilitado. ${ }^{23}$ Por lo pronto, para los dirigentes rusos lo importante no es el desarrollo del poderío bélico (eso no los hace pacifistas), sino, como en el caso de Estados Unidos, modernizar su planta industrial a fin de hacerla competitiva frente a sus rivales comerciales. Para lograr ese objetivo, exigirán a su pueblo nuevos y mayores sacrificios, más de los que ha tenido en los noventa.

Todas las demás potencias, el Reino Unido, Francia, Italia y, sobre todo, Japón y Alemania, están enfrascadas en un creciente rivalidad tecnológica comercial y de productividad para avanzar en las zonas de influencia de los otros rivales. Los dirigentes políticos de esos poderosos países también hacen y harán lo imposible para no desaparecer bajo las garras de sus rivales y si es posible, para ganar mercados y zonas de abastecimiento de materias primas, sobre todo estratégicas, así como influencia de todo tipo.

Especial atención hay que poner en China, que es la potencia de mayor vigor económico sostenido desde el fin de la revolución cultural, 1978-1979 hasta 1996. También el gobierno de este país tiene la necesidad de competir comercialmente con sus rivales; la experiencia histórica le ha demostrado que si China no se convierte en una potencia de primer orden nuevamente

23. "El financiamiento internacional de la conversión de la industria militar rusa se divide en dos categorías: el financiamiento directo de una parte se obtiene a través de todos los créditos procedentes de instituciones internacionales a países extranjeros [...] la ayuda norteamencana tal como la ayuda francesa está destınada a la conversión así como a impulsar a los industriales nacionales a participar en la misma [...] Su presencia en este terreno se lleva a cabo en la propia medida que lo permitan los capitales de inversıón aportados por el gobierno. La segunda categona no pasa por los concursos de ayuda especif1camente para la conversión sino por el aporte que significa la ayuda más general a Rusia. La Comunidad Económica Europea (ahora UE) abrió en 1992 una línea de crédito por 450 millones de ecus -50 millones más que el año anterior- para financiar las operaciones de asistencia técnica a los países de la CEI. De esa cantidad, 120 millones fueron exclusivamente destinados a Rusia." ONU, Le disarmement et la conversion de l'índustrue militaire en Russie, Research Papers/Travaux de Recherche, núm. 24, UNIDIR, 1995, p. 53. 
podrá ser conquistada ya sea económica o políticamente. Por tanto, para los gobernantes de esa gran nación está presente la necesidad de modernizar la planta industrial a fin de incrementar su competitividad, de un lado, pero del otro ello significará la reducción de 10 millones de trabajadores en 1997 y de otros 20 millones en 1998, según planteó en una conferencia el investigador mexicano Sergio de la Peña, después de haber realizado un viaje de estudio a ese país. Toda esta población trabajadora podrá ser reempleada en nuevas actividades, según estimaciones de los dirigentes chinos. Tal vez ello se logrará en la medida en que sea posible mantener las altas tasas de crecimiento de los años previos, pero si ello no ocurre así (no tenemos elementos que nos permitan predecir si seguirá creciendo a un gran ritmo la economía de China), no se podría absorber a la actual y futura fuerza de trabajo; tal vez la desocupación avanzaría. Con todo, sus aspiraciones hegemónicas como potencia nuclear del Pacífico no quedarían sepultadas.

En suma, tenemos tanto a las grandes potencias como a los países que aspiran a serlo; también a otros que no desean perder su posición de país importante en el orbe y por último a los que no aspiran a una ni otra cosa, o sea, todos aquellos como los de América Latina y la mayor parte de los de Asia y Africa, es decir, los que están supuestamente fuera de este juego, pero que en realidad están adentro, no como protagonistas sino como países víctimas que sólo podrán aspirar a evitar su desintegración, su recolonización con los avances globalizadores de las potencias.

Todos los países, de una forma u otra, están engarzados en la competencia y en la rivalidad comercial. Unos, la mayor parte, compitiendo mediante el ofrecimiento de mano de obra barata; otros, los menos, mediante el esfuerzo para aumentar la productividad a fin de acelerar sus exportaciones. Detrás, el paradigma del crecimiento económico y el desarrollo que también, como hemos visto, requiere la centralización del poder político y finalmente un establecimiento militar crecientemente modernizado en aras de la seguridad nacional, hoy día ${ }^{24}$ vinculada con la lucha contra el narcotráfico en el hemisferio occidental y en Asia y contra el terrorismo aún en Europa.

Tan fácil que sería resolver los problemas mundiales si en vez de la deificada y sacrosanta competencia, se pusiera en primer lugar la verdadera y genuina colaboración entre los seres humanos, empezando ahora por la atención a los pueblos más desvalidos del planeta. ${ }^{25}$

Creemos que, a pesar de la crisis del liberalismo histórico que hace tan compleja la lucha por la democracia, existe un elemento positivo en la lucha específica por el desarme nuclear en una coyuntura en que la centralización del poder político y económico desencadena fuerzas contrarias: descentralizadoras. En efecto, las tareas que se han derivado de esos elementos reunidos serían: rechazo masivo a las armas nucleares, desempleo global, tendencias descentraliza-

24. En 1997 los gastos totales del gobierno federal de Estados Unidos, la potencia mundial más avanzada, en investigación y desarrollo serán de 73.9 miles de millones de dólares, de los cuales 37592 millones, o sea el $50.8 \%$, representan gastos militares directos, ya que se destinarán a la defensa. Véase "R \& D Battelle", Research Funding Forecast. Magazine, enero de 1997, Columbus Ohio, p.3.

25. Emmanuel Wallerstein ha analizado la contradicción entre la aspiración liberal a los derechos humanos y la posibilidad real de atenderlos como tales. Véase, del autor, "Paz, estabilidad y legitimación, 1990-2025/2050", en Pablo Gonzáles Casanova (coord.). El mundo del siglo $\mathrm{XXI}$, recogido en Después del liberalismo, México, CIIH-UNAM y Siglo XXI Editores, 1996. 
doras opuestas al poder centralizado que podrían hacer más factible el logro de regiones y aún continentes enteros libres de armas nucleares, aspiración que en América Latina se ha sostenido por medio del Tratado de Tlatelolco. Si recordamos que el gobierno de Cuba recientemente se sumó al mismo, podemos creer que no se trata de un grano de arena, en esa aspiración a tener una zona continental desnuclearizada, sino de un compromiso, ya que en Cuba existen con tecnología nuclear para fines pacíficos (radioisótopos, entre otros), los que nada tienen en común con la bomba atómica; de otro modo aquel compromiso sería ilógico. Recientemente el Comité del Desarme, organización no gubernamental, dio a conocer su propuesta de creación de zonas libres de armas nucleares, la cual está contenida en un borrador de resolución, introducido por Brasil para el Hemisferio Sur y Zonas Adyacentes, para una Zona Libre de Armas Nucleares (NFWFZ). Esta propuesta ha sido copatrocinada por más de 60 estados, los que hacen un llamado a todos los gobiernos de las naciones relevantes para que ratifiquen los tratados emanados de la NFWFZ, para lo cual no se crea alguna obligación legal. Se trata sólo de reconocer la emergencia de una zona libre de armas nucleares. Paquistán introdujo una enmienda al texto de este Comité que especifica que Asia del Sur es una región donde se pueden negociar más zonas de estas características. Creemos que especialmente en los países del Sur ello es posible.

Para otros, como Estados Unidos, existen nuevas situaciones, como la que se dio en el seno de la Asamblea General de la ONU, que dan cuenta de una mayoría de votos negativos en torno a: resoluciones de desarme que incluyen conceptos contrarios a su política nuclear declarada, como la eliminación de las armas nucleares en un marco de plazos preestablecidos y negocia- ciones multilaterales. Se considera empera que éste es un récord ligeramente mejor que el de 1995, cuando Estados Unidos padeció ese aislamiento en dicha votación siete de once veces en lugar de los cuatro de seis ahora. ${ }^{26}$

\section{REFLEXIÓN. FINAL}

La revolución científico-tecnológica no se detendrá y con ella avanzarán los aspectos positivos y los destructivos de la misma mientras la humanidad sea incapaz no sólo de destruir todos los artefactos de la muerte que se han acumulado, sino de impedir la formación de un poder oligopólico (de los grupos dirigentes) de las grandes potencias para la posible utilización de las nuevas armas de destrucción que se elaboren. ¿Podrán alcanzarse esos objetivos? No lo sabemos, pero lo deseamos. De no lograrse lo anterior, la perspectiva es funesta para la humanidad en la medida en que haya más armas letales. La lucha por el poder mundial es el factor de impulso que está haciendo posible la investigación científico-militar...

26. Véase "How the Nuclear Powers Voted", en Disarmament Times, Vol. XX, núm. 7, 17 de diciembre de 1996. 